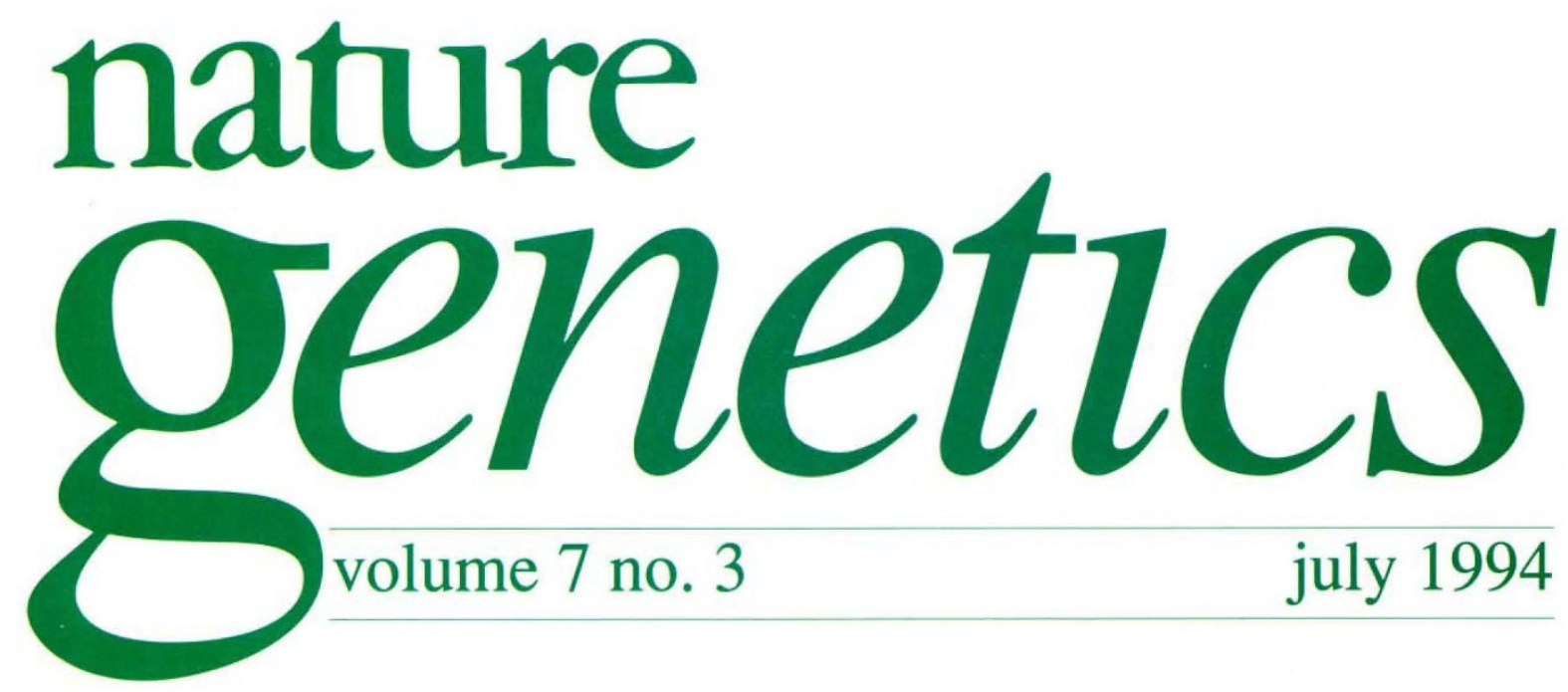

\title{
Prime suspect for cystic kidneys
}

The number of disease genes on the most wanted list has lost another notable member. And not before time. For the past ten years, there has been an intensive international effort to find the gene responsible for autosomal dominant (or adult) polycystic kidney disease (ADPKD) which has nevertheless stubbornly evaded capture. But now, Dr Peter Harris and his many colleagues in the European Polycystic Kidney Disease Consortium report in Cell $^{n}$ the gratifying results of their search to find the gene mutated in ADPKD. Their story has much in common with the ten year struggle to identify the Huntington's disease (HD) gene. If serendipity were available commercially, it would command the highest of prices.

Polycystickidney disease affects about 1 in 1,000 individuals, and is a progressively serious condition that often culminates in end-stage renal failure. The search for the major ADPKD gene began in earnest in 1985, just two years after the $H D$ gene was mapped, when the $P K D 1$ gene was placed ${ }^{2}$ somewhere near the tip of chromosome 16 . As with $\mathrm{HD}$, this was followed by the identification of closer markers, detailed genetic and later physical maps of the region and the cloning of numerous decoy genes. And as with $H D$ again, an international collaboration was necessary to compile haplotype patterns with which to search for meaningful signs of linkage disequilibrium and to scour the thousands of bases of candidate genes. But there was one important difference between the two efforts - whereas the HD collaborative group had no lucky breaks to lead them directly to their gene, a single family put the PKD1 consortium on the right track.

The all-important clue was actually provided by a Portuguese tuberous sclerosis family that was brought to the attention of Dr Julian Sampson and his Cardiff-based research group. 'Family 77 ' presented via an 11-year-oldboy, severely mentally retarded and with multiple signs of tuberous sclerosis. Cytogenetic analysis showed that whereas the healthy father has a normal karyotype, the mother has a balanced $t(16 ; 22)$ translocation that has been inherited by their daughter. Their son, the propositus, has inherited an unbalanced karyotype and has tuberous sclerosis, presumably because he is missing the tip of chromosome 16p and the associated tuberous sclerosis locus (TSC2), known to map to the same region of chromosome 16p13.3 (TSC1 maps on chromosome 9). The identity of TSC2 was revealed late last year by essentially the same consortium of European researchers; given the name tuberin, it turns out to be homologous to a GTPase activating protein ${ }^{3}$.

The surprising feature of Family 77 is that a closer examination of the mother and daughter showed that they have clinical symptoms of ADPKD, suggesting that the translocation had disrupted the PKD1 region. So two years ago, a consortium was formed by two groups predominantly interested in tuberous sclerosis, 
and two others with a longstanding interest in ADPKD. Collectively they set out to map the chromosomal breakpoint and look for transcripts from the critical region. Among other candidates, that search revealed a partial transcript (previously identified during the search for TSC2) that became, by virtue of its position within the breakpoint region, the prime suspect for $P K D 1$. But isolation of a more complete transcript (dubbed $P B P$, the polycystic breakpoint gene) was hampered by the partial duplication of the region on a more proximal area of the chromosome 16 short arm. Nevertheless, by applying Southern based screening of the 3 ' single copy fragment in ADPKD patients, Harris and colleagues detected genomic rearrangements and so, two years after discovery of the translocation, brought to a close the nineyear search.

Curiously, the sequence of about a third of the complete PKD1 transcript (estimated to be 14 kilobases) has not yet turned up any familiar homologies. One intriguing theory is that PKD results from the altered cell surface polarity of membrane proteins in kidney epithelial cells, but, for the moment, that remains conjecture. So too does the possibility that $P B P$ may harbour expanded triplet repeats, suggested by the sketchy evidence for anticipation in PKD. The duplication of the translocation breakpoint - and more than three-quarters of the $P B P$ gene - elsewhere on chromosome 16 will clearly impede efforts to complete the sequence and identify mutations. It is a little disappointing therefore that, for the time being at least, linkage analysis will remain the only DNA base method available for presymptomatic diagnosis of ADPKD.

Hopefully, the search for other genes involved in PKD will move a little quicker. Last year, two groups ${ }^{4,5}$ reported that a second dominant PKD gene maps to the long arm of chromosome 4 . This locus is probably responsible for $10-15 \%$ of all cases, and has a slightly later age-of-onset than PKD1. And on page 429 of this issue ${ }^{6}$, Dr Klaus Zerres and colleagues at the University of Bonn in Germany show that the gene for the recessive form of PKD is situated on chromosome 1. This form strikes far earlier than dominant, late-onset PKD, often in the prenatal period. Current screening methods employing ultrasound technology to detect the enlarged kidneys are notoriously unreliable, and the newly described markers should prove of immediate clinical usefulness. The evidence so far suggests that autosomal recessive $\mathrm{PKD}$ is a homogeneous disorder, and casts doubt on the notion recently put forward that the human counterpart of a murine transgenic model for PKD, which maps to chromosome 13 , is involved in some forms of human $\mathrm{PKD}^{7}$.

While the search for PKD1 ended in Oxford, where it kicked off nine years ago, a few familiar names were notable by their absence from the group of authors that made last month's announcement. In particular, Dr Stephen Reeders was first author of the paper in Nature that mapped PKD1 in 1985. After moving to Yale University shortly afterwards, his group doggedly tracked the gene, and Reeders says that they too had identified the terminal portion of the gene now shown to be responsible for ADPKD. Indeed, they first spotted the $P B P$ transcript as early as 1990 , but the large size of the gene placed it low on their list of priorities.

Reeders, who now works at the Brigham and Women's Hospital in Boston, admits that he grew frustrated by the tortuous progress in finding the gene and, in a departure not uncommon for disillusioned researchers, recently joined a New York venture capital firm, Helix Partners, which specializes in starting up new biotechnology companies. That some of these will be making PKD a top research priority goes without saying.

Like the PKD consortium, Reeders' group is faced with the daunting task of how to piece together the entire gene sequence. One strategy that may enable these groups to overcome the problem of duplications in this region is to assemble the coding regions together from the raw genomic sequence by sequencing cosmids from the breakpoint region.

So far, Harris and colleagues have learnt little about the normal role of the PKD1 protein or how mutations at this locus lead to cyst development. However, now that studying the protein is possible, and given the many groupsinterested in the biology of renal cystic disease, this is likely to become an area of increased activity and competition. Might it be that a further collaborative effort could make progress on this next phase a little faster?

1. The European Polycystic Kidney Disease Consortium. Cell 77, 881-894 (1994).

2. Reeders, S.T. et al. Nature $317,542-544$ (1985).

3. The European Chromosome 16 Tuberous Sclerosis Consortium. Cell 75, 1308-1315 (1993).

4. Peters et al. Nature Genet. 5, 359-362 (1993).

5. Kimberling et al. Genomics 18, 467-472 (1993).

6. Zerres, K. et al. Nature Genet. 7, 429-432 (1994).

7. Moyer, J.H. et al. Science 264, 1329-1333 (1994). 